\title{
Impact of Brake Pad Structure on Temperature and Stress Fields of Brake Disc
}

\author{
Guoshun Wang and Rong Fu \\ School of Mechanical Engineering, Dalian Jiaotong University, Dalian, Liaoning 116028, China \\ Correspondence should be addressed to Guoshun Wang; lianda_tian@126.com
}

Received 7 September 2013; Revised 3 November 2013; Accepted 4 November 2013

Academic Editor: Pavel Lejcek

Copyright (C) 2013 G. Wang and R. Fu. This is an open access article distributed under the Creative Commons Attribution License, which permits unrestricted use, distribution, and reproduction in any medium, provided the original work is properly cited.

Utilizing ABAQUS finite element software, the study established the relationship between a brake pad structure and distributions of temperature and thermal stress on brake disc. By introducing radial structure factor and circular structure factor concepts, the research characterized the effect of friction block radial and circumferential arrangement on temperature field of the brake disc. A method was proposed for improving heat flow distribution of the brake disc through optimizing the position of the friction block of the brake pad. Structure optimization was conducted on brake pads composed of 5 or 7 circular friction blocks. The result shows that, with the same overall contact area of friction pair, an appropriate brake pad structure can make the friction energy distribute evenly and therefore lowers peak temperature and stress of the brake disc. Compared with a brake pad of 7 friction blocks, an optimized brake pad of 5 friction blocks lowered the peak temperature of the corresponding brake disc by $4.9 \%$ and reduced the highest stress by $10.7 \%$.

\section{Introduction}

Disc brake is widely used currently for high-speed train braking. It transforms dynamic energy into heat energy by utilizing friction between brake pad and brake disc and then dissipates the heat energy through heat exchange. This process involves heat transfer, structural features, mechanical characteristics, material properties, and other aspects and is a complex thermal-mechanical coupling process. Focusing on brake pressure, brake disk, brake mode, brake pad material, and other factors, domestic and foreign scholars have conducted many studies on the brake disc temperature and stress in the braking process through test experiments and finite element analyses. Chung Kyun Kim and so forth [1-4] studied the temperature field and stress field of brake disc. To lower the calculation difficulty and cost, they simplified brake disc into a $2 \mathrm{D}$ axisymmetric model, assuming that heat flow transmission and contact condition are unrelated to circular coordinate changes of the brake disc. The simplified 2D axisymmetric model, however, ignored the flow of the heat source. Based on axisymmetrical hypothesis, papers [58] chose one of symmetrical round angles of brake disc as analysis target, established 3D circular symmetrical finite element model of the brake disc, and studied the temperature field and stress of the brake disc. Relative to the 2D model, the 3D circularly symmetrical model had some improvements but still ignored the impact of periodical contact between brake disc frictional area and brake pad in the braking process. Papers [9-12] considered the impact of frictional heat source flow, established 3D whole disc model, and calculated the nonaxisymmetrical transient temperature field of brake disc. The studies considered the impacts of brake pad shape, instantaneous angular velocity, radial position, and so forth but did not include the impact of the shape and structural layout of brake pad friction blocks upon brake disc temperature and stress.

The structure differences of friction blocks of a brake pad can lead directly to differences in friction contact time and friction speed at each point on the brake disc surface, result in uneven temperature distribution on the brake disc surface, consequently cause high thermal stress, and therefore exacerbate the brake disc thermal fatigue. It is an important topic to study the relationship between the structure of 
the friction blocks of the brake pad and the temperature field of the brake disc.

Starting from the relations between the friction block structural difference of the brake pad and the temperature and stress fields of brake disc, this paper establishes a connection between friction block structures of brake pad and temperature and stress distribution characteristics of brake disc, optimizes the structure and arrangement of the brake pad friction blocks, analyzes the variation of brake disc temperature and stress with the optimized brake pad, and finally validates the findings by sequential coupling simulations with ABAQUS6.8 finite element software.

\section{Disc Brake Finite Element Model and Thermal Boundary Conditions}

2.1. Simplification of Disc Brake Friction Pairs. Disc brake assembly consists of brake dick, disc braking element, brake pad, lever, and other parts. It would greatly increase the simulation difficulty and analysis time if including all the parts in the finite element model. Only the brake disc and brake pad are considered when creating the model. Furthermore, the disc (Figure 1) and the pad (Figure 2) both have symmetry; the analysis is on the friction pair of one side of the disc friction surface and half of the pad (Figure 3).

2.2. Analysis Assumptions. Friction braking is a complex process involving friction wear, deformation, vibration, and so forth. It is also a process of interactions of multiple physical, chemical, and mechanical changes. To simplify the analysis models, the following assumptions are made:

(i) neglect the effect of the roughness and friction wear of the friction pair contact surfaces;

(ii) the contact of the friction pair is face to face contact;

(iii) the braking pressure is distributed evenly on the friction blocks;

(iv) the heat dissipation of the brake disc is mainly through convection and radiation during braking and neglect the conduction of heat between the disc and the shaft;

(v) the physical properties of the friction blocks do not change with temperature in the braking process.

\subsection{Thermal Boundary Model}

2.3.1. Thermal Input. In the process of braking, the thermal energy generated from the kinetic energy can be divided into two parts: the majority of the heat is first absorbed through conduction by the brake disc and the pads and then gradually dissipated after the braking into the surrounding environment; the other part is rather emitted into the surrounding environment directly off the friction surface through convection and radiation. This paper assumes that $90 \%$ of the total kinetic energy is converted into friction thermal energy which is absorbed by the disc and the pads.

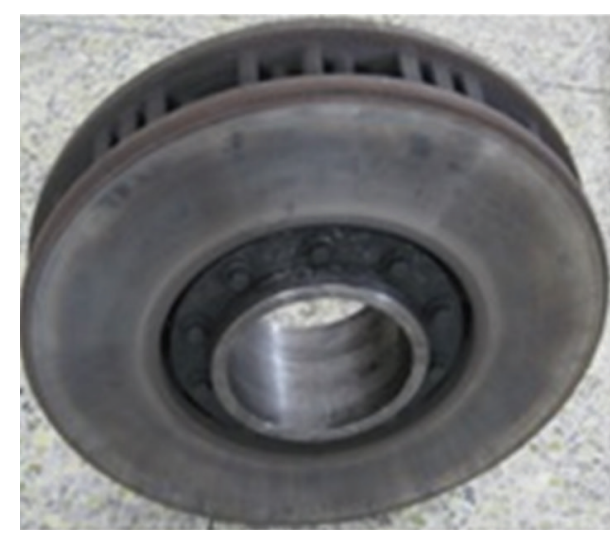

FIgURE 1: Brake disc.

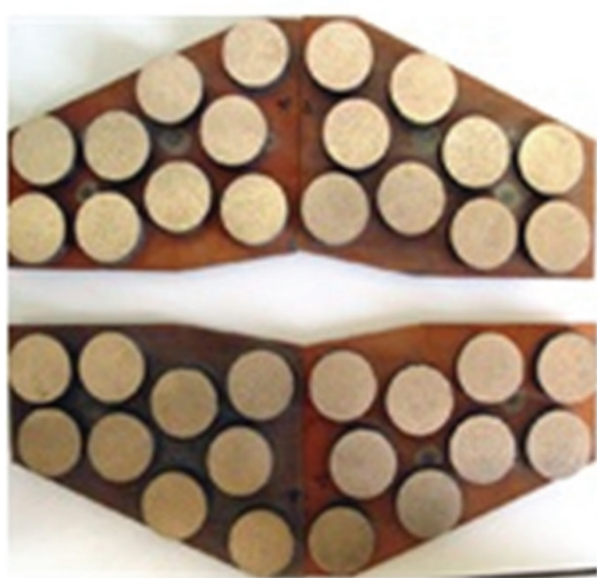

FIgURE 2: Brake pads.

How to distribute the friction heat between the friction pair is also needed to be considered when establishing the finite element analysis model. The current approach is to set a thermal distribution ratio that artificially distributes the thermal energy to the disc and the pads. The ABAQUS software used in this study uses constant thermal energy distribution factor which has a default value of 0.5 , or $50 \%$ of the thermal energy is taken by the disc and the other $50 \%$ by the pads.

2.3.2. Convection Model. Because the brake disc rotates at high speed, the convection coefficient of the brake disc changes with the disc speed during braking. For convection heat exchange based on convection heat transfer theory,

$$
\mathrm{Nu}=0.337 \times \operatorname{Re}^{0.8} \operatorname{Pr}^{0.35}
$$

And simultaneously,

$$
\mathrm{Nu}=h_{c} \frac{L}{\lambda}
$$

Therefore, the convection coefficient $h_{c}$ is

$$
h_{c}=\frac{\lambda \mathrm{Nu}}{L}=\frac{0.337 \times \operatorname{Re}^{0.8} \operatorname{Pr}^{0.35} \times \lambda}{L} \text {, }
$$




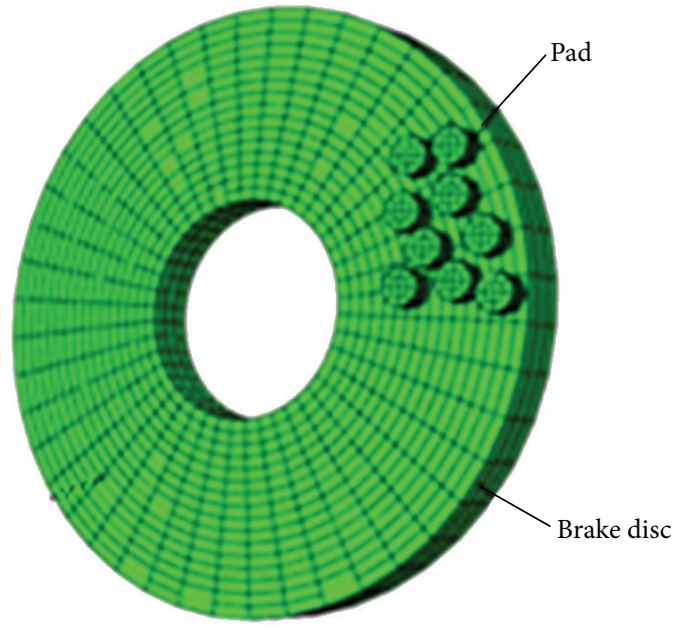

Figure 3: Brake pad and brake disc finite element model.

where $\mathrm{Nu}$ is Nusselt number, Re is Reynolds number of air, $\mathrm{Pr}$ is Prandtl number which is set to $0.7, \lambda$ is the thermal conductivity coefficient which is $6.14 \times 10^{-6} \mathrm{~W} / \mathrm{mK}$, and $L$ is the characteristic length of the disc. $L$ in this case takes the circumference at the location of the point, $L=2 \pi r$, where $r$ is the radius of the point.

The Reynolds number Re of air is calculated as in the following equation:

$$
\operatorname{Re}=\frac{v L}{\beta},
$$

where $v$ is the velocity of the point and $\beta$ is the air viscosity.

Therefore, the convection coefficient $h_{c}$ is

$$
h_{c}=\frac{\lambda \mathrm{Nu}}{L}=\frac{0.337 \operatorname{Pr}^{0.35}\left(\lambda / \beta^{0.8}\right)(r \omega)^{0.8}}{L^{0.2}}
$$

in which $\omega$ is the anglar velocity of the brake disc.

Substitute Newton's cooling equation $q=-h_{c} \Delta T$ into (5) to have the convection heat transfer model:

$$
q=-h_{c} \Delta T=\frac{0.337 \operatorname{Pr}^{0.35}\left(\lambda / \beta^{0.8}\right)(r \omega)^{0.8}}{L^{0.2}} \Delta T .
$$

2.3.3. Thermal Radiation Boundary. This study applies Newton's law of cooling and Stefan-Boltzmann equation to convert heat radiation to convection heat transfer coefficient. Take the brake disc emissivity $\varepsilon=0.75$; the equivalent convection heat transfer coefficient is then

$$
\alpha_{r}=0.75 \times 0.567 \times 10^{-8}\left(T_{1}^{2}+T_{2}^{2}\right)\left(T_{1}+T_{2}\right),
$$

where $T_{1}$ is the surface temperature of the disc and $T_{2}$ is the ambient temperature.

2.4. Parameters of Physical Properties of Materials. Refer to Table 1 for related parameters of brake disc and friction blocks. Brake disc is made of 28CrMoV5-08, and brake pad is made of copper base powder metallurgy materials. The properties of the materials are in Table 2. The brake pressure is $0.56 \mathrm{MPa}$, the friction coefficient is 0.34 which is the average of measured data, and the initial temperature of the friction pairs is $20^{\circ} \mathrm{C}$.

\section{Results and Discussion}

The calculation is done in ABAQUS by sequential coupling method. Refer to Table 3 for information about the mesh. In order to improve the simulation accuracy, 8-node hexahedral element is selected and the element size is less than $4.5 \mathrm{~mm}$ to ensure that at least 5 nodes in radial direction on each friction block of $20 \mathrm{~mm}$ radius are in contact with the brake disc.

\subsection{Calculation of Temperature Field and Stress Field of the} Brake Disc. Figure 4 is the temperature distribution on the brake disc surfaces which have the same total friction area. The disc is under constant deceleration of $0.9 \mathrm{~m} / \mathrm{s}^{2}$ from an initial speed of $120 \mathrm{~km} / \mathrm{h}$. The temperatures and temperature distributions of the brake disc surfaces of the 3 brake pads are apparently different. At the initial braking phase (Figure 4(a)), the peak temperatures of the disc surfaces are more nonuniformly distributed in radial direction. The maximum temperature on the surface of brake disc A1 is relatively low. There are 3 distinct high temperature rings on the surface of brake disc A2 and a high temperature zone with larger radial width on the surface of brake disc A3. At the end of the braking (Figure 4(b)), the temperature distributions on brake disc surfaces become more uniform because the generated heat diffuses and overlays as friction goes on. The maximum temperature on the surface of brake disc A1 is lower and the temperature on the surface of brake disc A3 is higher.

Figure 5 is the variations of stress of brake disc surfaces in radial direction. Obviously, at the brake time of $10 \mathrm{~s}$ (after the disc rotates 103.2 revolutions) (Figure 5(a)), the peak stress of the brake disc A1 is $50 \mathrm{MPa}$. The disc A2 shows three stress peaks with the largest one of $53 \mathrm{MPa}$. The stress peak value of brake disc A3 is $55 \mathrm{MPa}$. Comparing the three brake pads, the peak stress of $\mathrm{A} 3$ is $10 \%$ higher than that of $\mathrm{A} 1$. When braking stops ( $t=36 \mathrm{~s}$, the disc rotation of 220.4 revolutions) (Figure 5(b)), the stress distributions on the three brake pads have similar trend with the increase in disc radii.

The above results show that for different structures of brake pads, the distributions of the generated friction heat are different, and, as a result, the values and distributions of the peak temperatures and stresses on the brake disc surfaces are different. For brake disc A1, the friction blocks are distributed more evenly on its surface, the overlaying of friction heat decreases, and the brake disc surface temperature and stress are the lowest. For disc A2, the surface temperature and stress fluctuate the most at the initial braking phase. Brake disc A3 has the highest temperature at the end of the braking because the friction radii of the centers of the contact areas of the multiple friction blocks are basically the same, and the friction heat is superimposed leading to high variation in temperature and stress. 


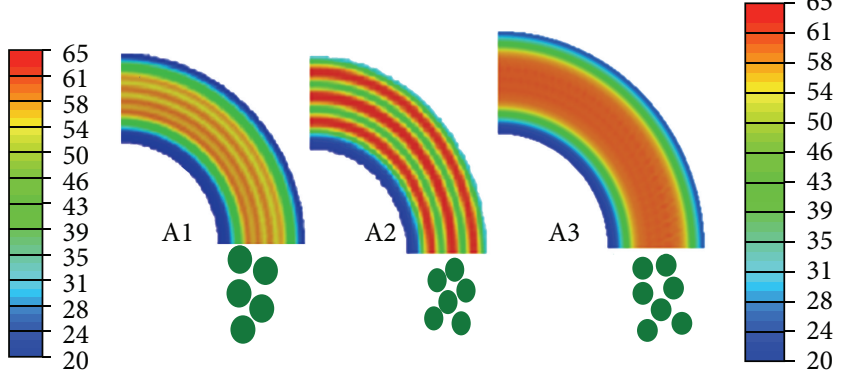

(a) Brake time $10 \mathrm{~s}$

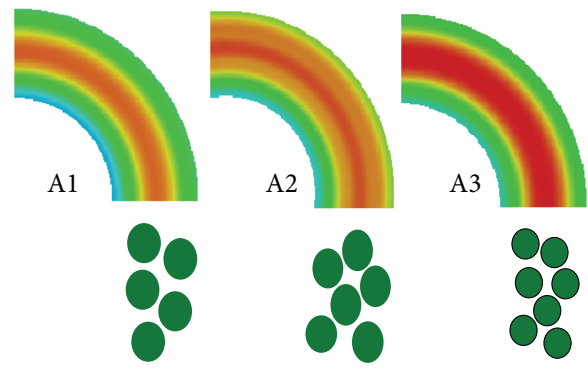

(b) Brake stop $t=36 \mathrm{~s}$

FIGURE 4: Distribution of brake disc surface temperatures of different structures of brake pads.

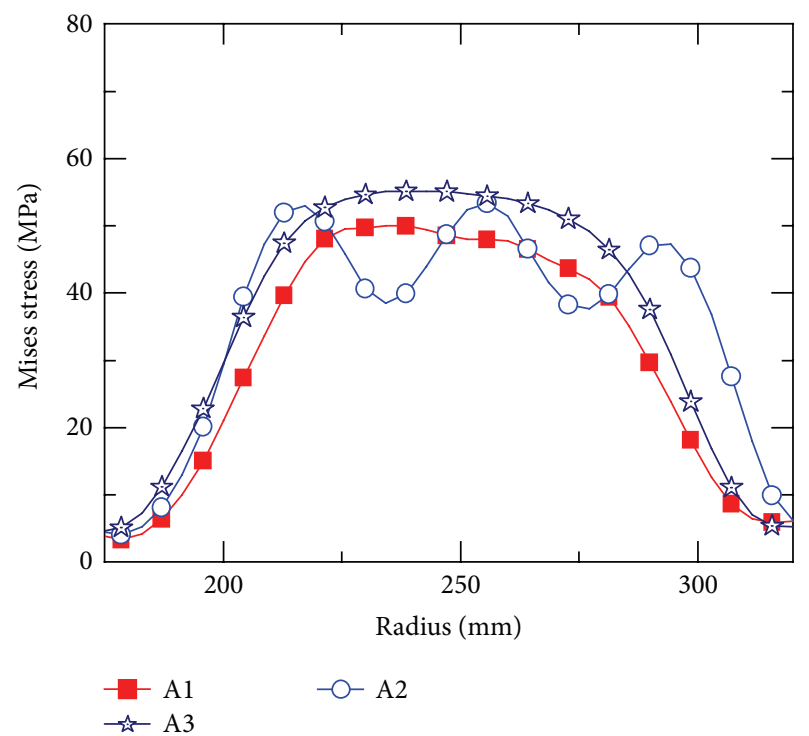

(a) $t=10 \mathrm{~s}$

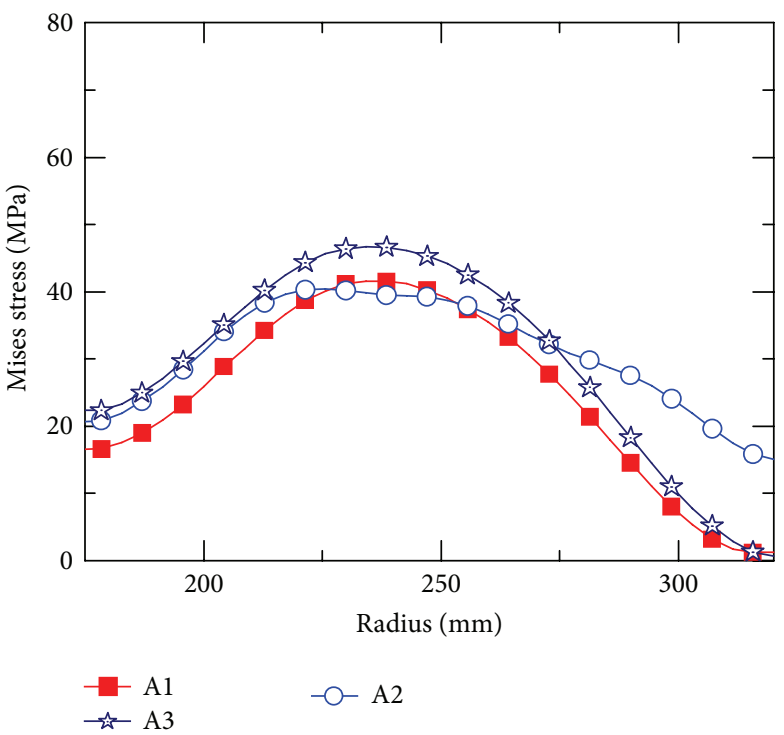

(b) $t=36 \mathrm{~s}$

FIGURE 5: Variations of brake disc Mises stress in depth direction.

\subsection{Structural Factor of Brake Disc}

3.2.1. Introduction of the Radial Structural Factor. Assuming that the energy produced by friction is distributed uniformly in circumferential direction of the brake disc, the heat source produced by the friction pair of the brake pad and brake disc moves relative to the brake disc in the braking process. Therefore, the heat flow density into any differential arc block of the brake disc shall be the ratio of the total heat entering the brake disc and the covered area of the brake disc by the differential arc block. Then the heat flow density [13] at the position $r$ of the brake disc is

$$
q(r, t)=\eta \mu \frac{F}{S} \cdot \frac{v_{t}}{R} \cdot r=\eta \mu \frac{F}{S} \omega r
$$

where: $S$ is total area of the brake pad, $\mathrm{m}^{2} ; F$ is force acted on brake pad, $N$; $R$ is radius of the wheel radius, $m ; \mu$ is friction coefficient between the brake disc and brake pad; $\omega$ is angular velocity of brake disc, $\mathrm{rad} / \mathrm{s} ; \eta$ is thermal efficiency flowing in to brake disc; $v_{t}$ is brake speed of train, $\mathrm{m} \cdot \mathrm{s}^{-1}$.
If dividing the friction area of the disc into $n$ rings of different radii, any such ring will have different effective friction area. The energy through any friction ring of radius $r_{i}$ with friction contact area $S_{i}$ in a unit time is

$$
Q\left(S_{i}\right)=\eta \mu \frac{F}{S} \omega r_{i} S_{i}, \quad i=1,2,3, \ldots, n
$$

The total thermal energy on the contact surface in a unit time is as following:

$$
Q(S)=\sum_{i=1}^{n} Q\left(S_{i}\right)=\eta \mu \omega \frac{F}{S} \sum_{i=1}^{n} r_{i} S_{i} .
$$

From Formula (9), the friction heat on brake disc is proportional to the friction radius of the friction pair on the brake disc and the friction area of the friction pair. The percentage of energy produced on any contact radius in unit time out of total energy will reflect the structural features 
TABLE 1: Geometric parameters of brake disc and cylindrical friction blocks.

\begin{tabular}{lccccc}
\hline & \multicolumn{2}{c}{ Brake disc size $(\mathrm{mm})$} & \multicolumn{2}{c}{ Friction block size $(\mathrm{mm})$} \\
\hline Inner diameter & Outer diameter & Thickness & Wheel radius & Friction block radius & Friction block height \\
\hline 116 & 320 & 20 & 445 & $20,21,22.5,23$ & 20
\end{tabular}

TABLE 2: Properties of friction pair materials.

\begin{tabular}{ccccccc}
\hline & $\begin{array}{c}\text { Density } \\
(\rho) \mathrm{kg} \cdot \mathrm{m}^{-3}\end{array}$ & $\begin{array}{c}\text { Elastic modulus } \\
(E) \mathrm{GPa}\end{array}$ & $\begin{array}{c}\text { Poisson } \\
\text { ratio }(v)\end{array}$ & $\begin{array}{c}\text { Thermal conductivity } \\
\text { coefficient }(\lambda) \\
\mathrm{W} /\left(\mathrm{m} \cdot{ }^{\circ} \mathrm{C}\right)\end{array}$ & $\begin{array}{c}\text { Specific thermal } \\
\text { capacity }(C p) \\
\mathrm{J} /\left(\mathrm{kg} \cdot{ }^{\circ} \mathrm{C}\right)\end{array}$ & $\begin{array}{c}\text { Thermal expansion } \\
\text { coefficient } \\
\times 10^{-6 \circ} \mathrm{C}\end{array}$ \\
\hline Brake disc & 7850 & 202 & 0.29 & 32 & 477 & 12.3 \\
Brake pad & 5500 & 180 & 0.3 & 74 & 436 & 11.1 \\
\hline
\end{tabular}

of the brake pads, and this ratio can be defined as radial structure factor (RSF) $f_{i}$ :

$$
f_{i}=\frac{q_{i}}{q} \times 100 \%=\frac{r_{i} S_{i}}{\sum_{i=1}^{n} r_{i} S_{i}} \times 100 \%, \quad(i=1,2,3, \ldots, n) .
$$

From the point of view of energy, $f_{i}$ can represent the difference in distribution of the brake disc structure. The larger the radial structural factor on a friction ring, the higher the energy and temperature generated.

\subsubsection{The Process of Calculating the Radial Structural Factor.} The following will illustrate the process of calculating the radial structural factor through an example (Figures 6 and 7). The geometric parameters of the brake disc and pad are listed in Table 4. Three circular friction blocks of the same radius are located arbitrarily on the disc friction surface which is divided into seven equal distance rings of equal radial distance (or the ring thickness) $H$ of $17.22 \mathrm{~mm}$. The criteria in choosing the $H$ are to ensure that there are at least three friction rings under each friction block.

The area of each ring is as shown in Figure 7.

The center radii of the seven friction rings are calculated based on the ring thicknesses and listed in Table 5 .

The areas of the rings $S_{1} \sim S_{7}$ are calculated in AutoCAD and are listed in Table 6.

The corresponding radial structural factors, as shown in Table 7, are calculated according to formula (4).

Table 7 shows that the radial structural factors are relatively large with high variation and will lead to high temperature and large temperature difference on the brake disc. Optimization to the pad structure would be required.

3.2.3. Circumferential Structural Factor. For the impact of brake pad structure on the friction heat distribution on the brake disc in circumferential direction, we adopt the circumferential structural factor, which is defined as the ratio of clearance area $S_{c}$ between friction blocks to total area $S_{t}$ of friction contact area of friction blocks multiplied by $m$, the number of friction blocks on the same friction ring:

$$
\varepsilon=\frac{S_{c}}{S t} \cdot m
$$

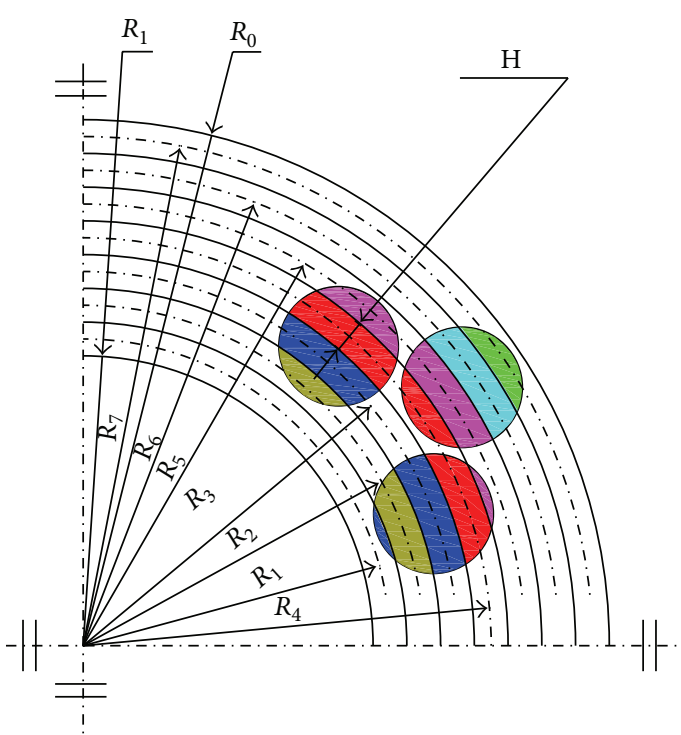

FIGURE 6: Friction ring illustration.

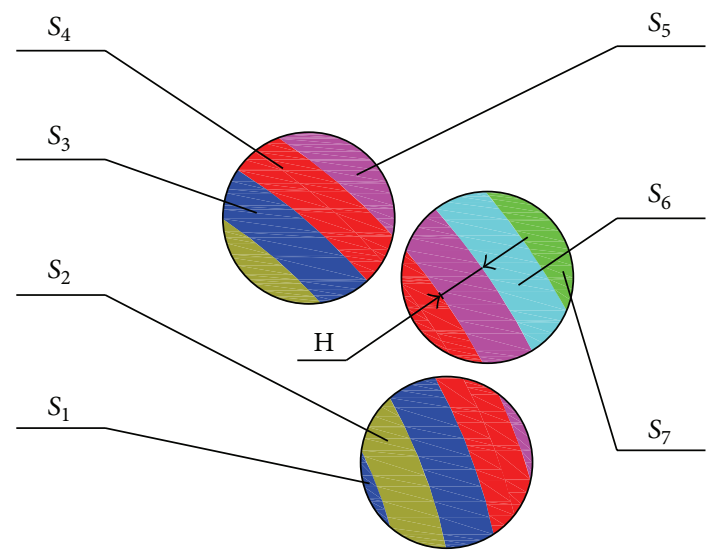

Figure 7: Areas of friction rings.

The lager the circumferential structural factor, the lager the diversion of the brake pad in the circumferential direction. 
TABLE 3: Information on finite element mesh.

\begin{tabular}{|c|c|c|c|c|}
\hline & $\begin{array}{l}\text { Number of } \\
\text { nodes }\end{array}$ & $\begin{array}{l}\text { Number of } \\
\text { elements }\end{array}$ & Element type & Element abbreviation \\
\hline Brake disc & 28917 & 24192 & \multirow{7}{*}{$\begin{array}{l}\text { 8-Node thermal } \\
\text { coupling hexahedral } \\
\text { element with reduced } \\
\text { integration }\end{array}$} & \multirow{7}{*}{ C3D8RT } \\
\hline A1 & 1560 & 879 & & \\
\hline $\mathrm{A} 2$ & 1872 & 1053 & & \\
\hline A3 & 2183 & 1228 & & \\
\hline Brake pads & & & & \\
\hline B1, B2 & 1590 & 987 & & \\
\hline B3, B4 & 2275 & 1487 & & \\
\hline
\end{tabular}

TABLE 4: Geometric parameters of the block and pad.

\begin{tabular}{lccc}
\hline \multicolumn{2}{c}{ Disc dimension $(\mathrm{mm})$} & \multicolumn{2}{c}{ Pad dimension $(\mathrm{mm})$} \\
\hline $\begin{array}{l}\text { Inner } \\
\text { radius }\end{array}$ & $\begin{array}{l}\text { Outer } \\
\text { radius }\end{array}$ & $\begin{array}{c}\text { Number of } \\
\text { blocks }\end{array}$ & $\begin{array}{c}\text { Radius of } \\
\text { friction block }\end{array}$ \\
\hline 147.97 & 268.52 & 3 & 30 \\
\hline
\end{tabular}

TABLE 5: Center radius of friction rings.

\begin{tabular}{lcccccc}
\hline \multicolumn{7}{c}{ Center radius of friction ring $(\mathrm{mm})$} \\
\hline$R_{1}$ & $R_{2}$ & $R_{3}$ & $R_{4}$ & $R_{5}$ & $R_{6}$ & $R_{7}$ \\
\hline 156.58 & 173.80 & 191.02 & 208.25 & 225.47 & 242.69 & 259.91 \\
\hline
\end{tabular}

TABLE 6: Areas of friction rings.

\begin{tabular}{lcccccc}
\hline \multicolumn{7}{c}{ Areas of friction rings $\left(\mathrm{mm}^{2}\right)$} \\
\hline$S_{1}$ & $S_{2}$ & $S_{3}$ & $S_{4}$ & $S_{5}$ & $S_{6}$ & $S_{7}$ \\
\hline 85.62 & 1155.54 & 1959.88 & 2294.09 & 1566.58 & 986.16 & 434.42 \\
\hline
\end{tabular}

3.3. Structural Optimization of Brake Pads. There is a corresponding relationship between the radial structural factor and the circumferential structural factor of a brake pad and the temperature field and thermal stress field of the brake disc. The fluctuation of the radial structural factor can impact the disc surface temperature and distribution of the stress field. Therefore, the temperature field and thermal stress distribution of a brake disc can be improved by reducing the fluctuation of radial structural factor, lowering the largest radial structural factor and increasing the circumferential structural factor.

A program for brake pad optimization is written in MATLAB. Firstly, program the friction block positions and limit the moving range of the blocks. Secondly, calculate all radial structural factors under the friction block arrangement on any friction ring of the brake disc at certain increment. Draw the distribution curve of radial structural factors in radial direction, calculate the difference $C$ between maximum value $M$ and minimum value $N$ on the curve, and make the difference smaller than a set value a by adjusting the radial arrangement of the friction blocks to determine corresponding brake pad structure. This brake pad structure is then the most optimized brake pad structure. The process is referred to in Figure 8.

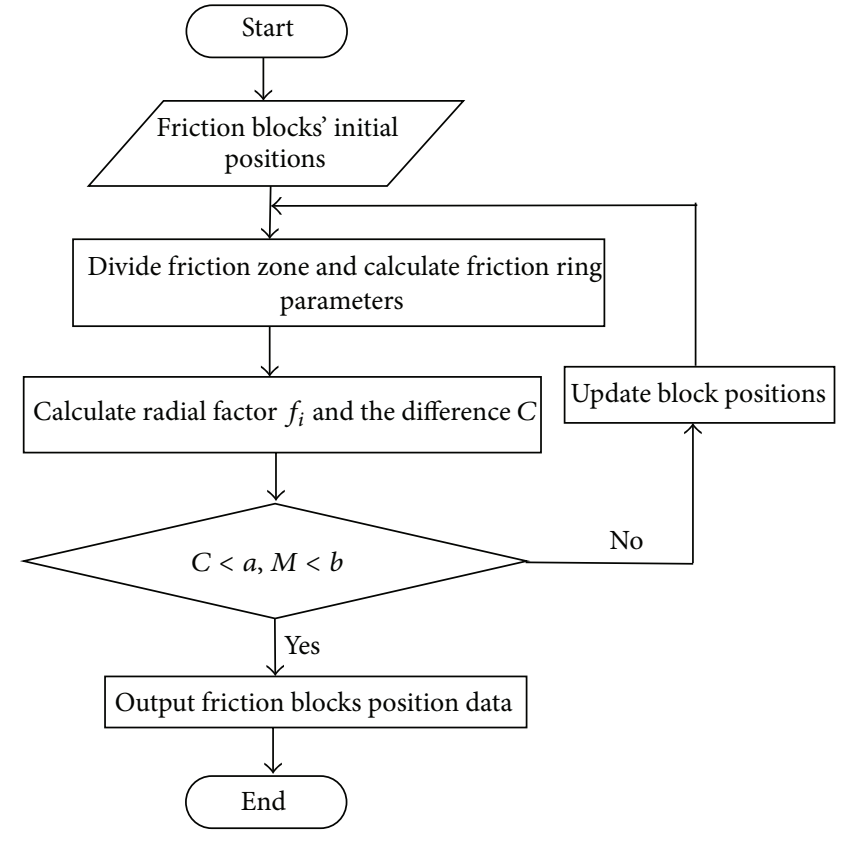

FIGURE 8: MATLAB program flow chart.

Table 8 is the A1 data of optimized brake pad structure of 5 friction blocks, in which $r$ is the friction ring radius of friction block center on the brake disc and $\theta$ is the circumferential angle (Figure 9) of friction block center on the brake disc. Refer to Figure 10 for the optimized brake pad structure obtained on basis of the above data and nonoptimized brake pad structure model.

Figure 11 shows the nodal temperature distributions on the disc surface corresponding to the brake pads formed by 5 and 7 cylindrical friction blocks before and after optimization. The braking speed is $80 \mathrm{~km} / \mathrm{h}$ and the friction time is $5 \mathrm{~s}$. The temperature field distribution on corresponding disc surface after optimization is more uniform and temperature difference is not large. On the other hand, there is an apparent high temperature strip on the disc surface before the optimization, and the maximum temperature occurs at the radius of the largest contact area with the brake pad. The uniformity of temperature field distribution after the optimization is obviously better than that before the optimization. 
TABLE 7: Radial structural factors.

\begin{tabular}{lccccccc}
\hline$n$ & 1 & 2 & 3 & 4 & 5 & 6 \\
\hline$r_{i} S_{i}$ & 13406.38 & 200850.23 & 374376.28 & 477744.24 & 353198.76 & 239331.17 \\
$\sum_{i=1}^{n} r_{i} S_{i}$ & & & 1771817.16 & & & \\
$f_{i}$ & 0.76 & 11.34 & 21.13 & 26.96 & 19.93 & 13.51 & 6.37 \\
\hline
\end{tabular}

TABLE 8: Data of optimized pad structure.

\begin{tabular}{lccccccc}
\hline Serial number & 1 & 2 & 3 & 4 & 5 & 6 & 7 \\
\hline $\begin{array}{l}\text { In friction ring } \\
\text { radius } r(\mathrm{~mm})\end{array}$ & 202 & 217 & 240 & 262 & 284 & & \\
$\begin{array}{l}\text { Circumferential } \\
\text { angle } \theta\left({ }^{\circ} \mathrm{C}\right)\end{array}$ & 12.3 & 41.5 & 26.6 & 13.26 & 34.25 & & \\
$\begin{array}{l}\text { In friction ring } \\
\text { radius } r(\mathrm{~mm})\end{array}$ & 214 & 228 & 245 & 260 & 265 & 291 & 291 \\
$\begin{array}{l}\text { Circumferential } \\
\text { angle } \theta\left({ }^{\circ} \mathrm{C}\right)\end{array}$ & 14.95 & 28.36 & 5.46 & 18.56 & 35.24 & 9.65 & 26.85 \\
\hline
\end{tabular}

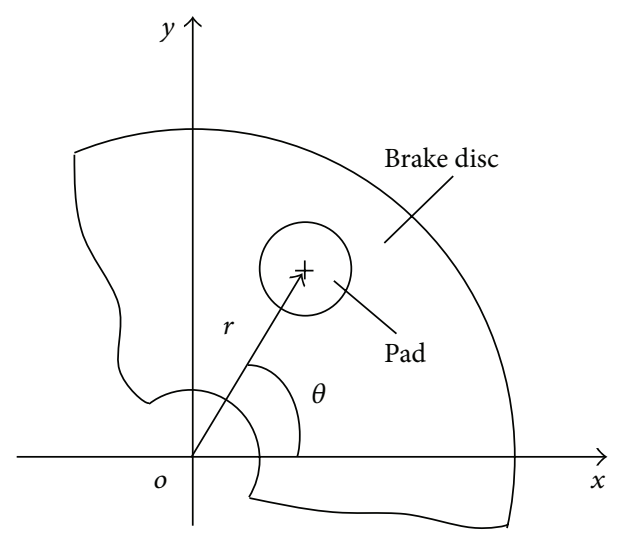

FIgURE 9: Diagram of friction pair.

Figure 12 shows the radial distribution curves of nodal temperatures on the brake disc surface. The maximum temperature on the surface of brake disc $\mathrm{B} 1$ is $33.1^{\circ} \mathrm{C}$, and the maximum temperature on brake disc $\mathrm{B} 2$ is $43.4^{\circ} \mathrm{C}$. The maximum temperature drops by $24 \%$ on disc surface pairing with the brake pad of five friction blocks after optimization. The maximum temperature on brake disc $\mathrm{B} 3$ surface is $34.8^{\circ} \mathrm{C}$, and the maximum temperature on brake disc B4 surface is $49.8^{\circ} \mathrm{C}$. The maximum temperature decreases by $30 \%$ on the disc surface pairing with the brake pad of seven friction blocks after optimization. The maximum temperature on the disc surface corresponding to the optimized pad of five friction blocks decreases by $4.9 \%$ compared to the maximum disc temperature caused by the optimized pad structure of 7 friction blocks.

Figure 13 shows the relationship curves between radial structural factor and friction radius of brake pad. Curves $\mathrm{B} 1$ and B3 are of optimized brake pads and B2 and B4 are of radial structural factors of nonoptimized brake pads. Obviously, B1 and B3 fluctuate less, and the corresponding disc surface temperature distributions are more uniform

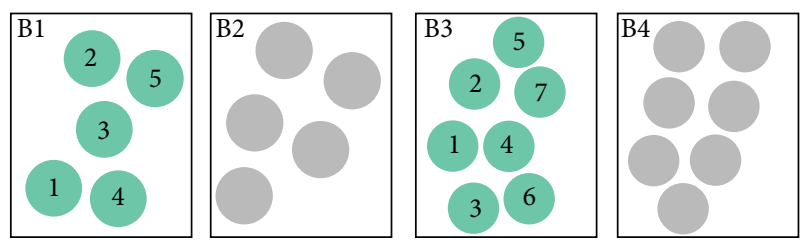

Figure 10: Numerical model of friction blocks arrangement (optimized: B1 and B3, nonoptimized: B2 and B4).

(Figure 12). B2 and B4 fluctuate more and have increased nonuniformity in the disc surface temperature distributions (Figure 11). The matching disc temperature decreases as circumferential structural factor increases. Thus in terms of structural factors, $\mathrm{B} 1$ and $\mathrm{B} 3$ structures are superior to $\mathrm{B} 2$ and B4 structures.

Comparing Figures 12 and 13, there is a certain consistency between the nodal temperature distributions and the structural factors, which demonstrates that the surface nodal temperatures of the brake disc and the structural factors in radial direction have the same trend and they have a corresponding relationship.

Figure 14 is the radial distribution curve of thermal stress on brake disc surface. For the optimized brake pad of 5 friction blocks, the largest stress on brake disc Bl surface is 22.6 Mpa, and for the nonoptimized brake pad of 5 friction blocks, the largest stress on brake disc B2 surface is $32.3 \mathrm{Mpa}$. The maximum stress on brake disc surface decreases by $31.3 \%$ after optimization. For the brake pad of 7 friction blocks, the largest stress on brake disc B3 surface is $25.3 \mathrm{MPa}$, and for the nonoptimized brake pad of 7 friction blocks, the highest stress on brake disc B4 surface is $38.2 \mathrm{Mpa}$. The largest stress on brake disc after optimization decreases by $33.7 \%$ than that before the optimization. The largest stress on optimized brake pad of 5 friction blocks decreases by $10.7 \%$ than that on optimized brake pad of 7 friction blocks.

\section{Conclusion}

(i) With the same total contact area of friction pair, the number and arrangement of friction blocks can impact the temperature and stress on the brake disc surface. An appropriate brake pad structure can make friction energy distribution more uniform to lower peak temperature and stress.

(ii) Based on the relationship between the features of friction blocks arrangement and the heat distribution on brake disc surface, the concepts of radial structural factor and circumferential structural factor are 

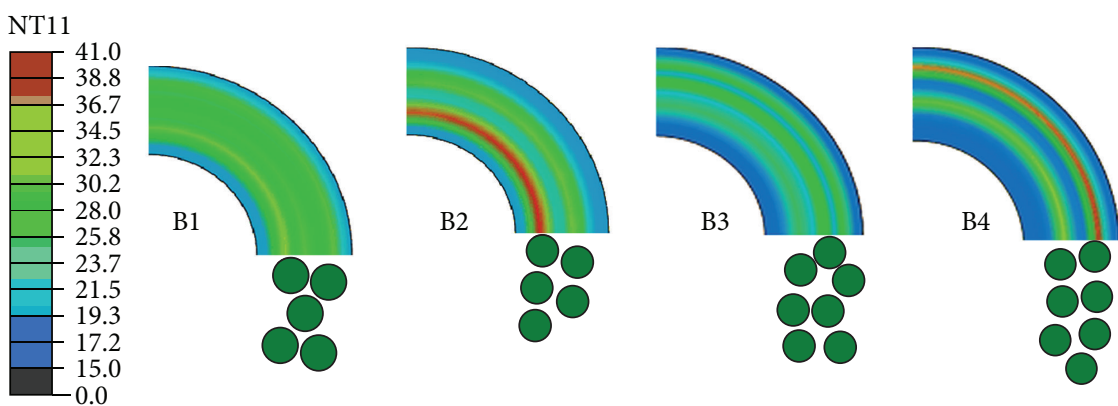

FIgURE 11: Nodal temperature distribution on brake disc.

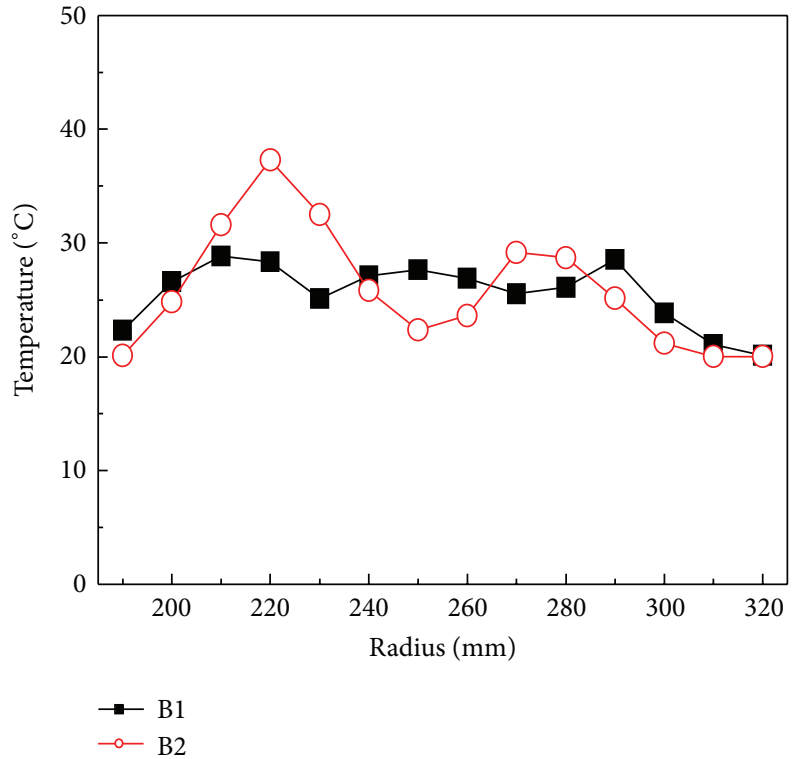

(a)

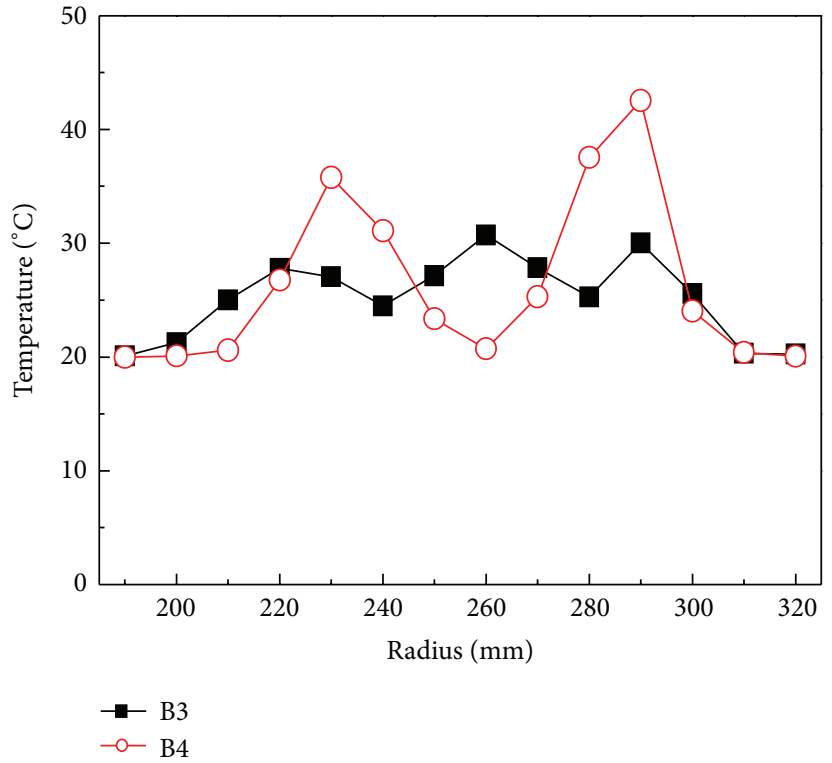

(b)

FIGURE 12: Relationship between nodal temperature and friction radius.

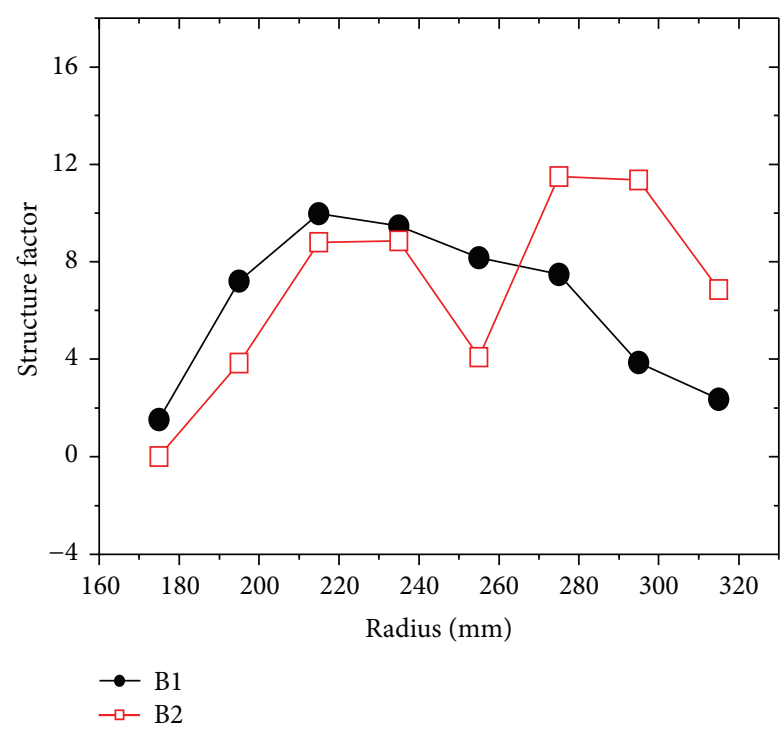

(a) Brake pad of 5 round friction blocks

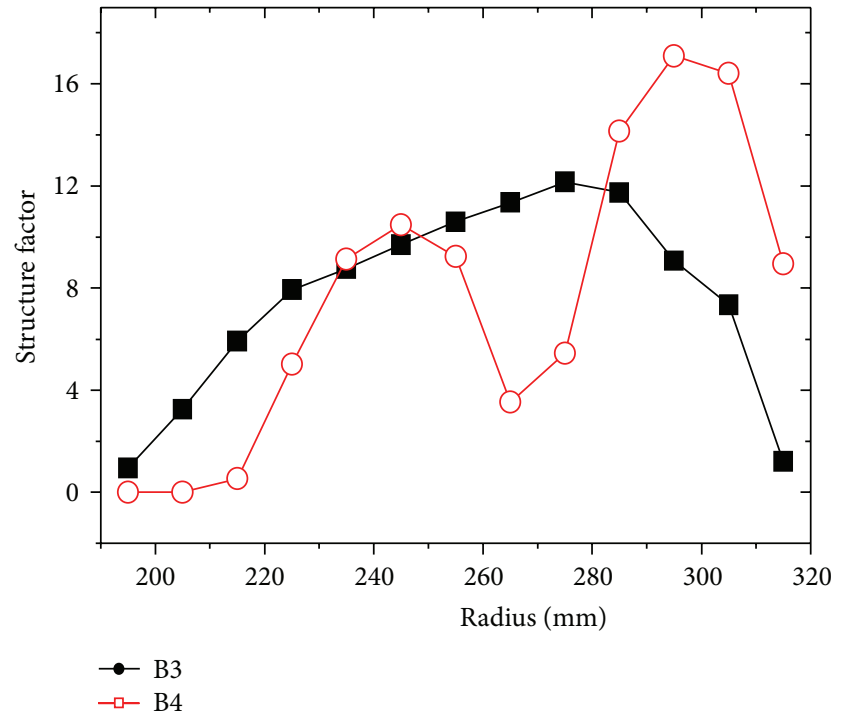

(b) Brake pad of 7 round friction blocks

FIGURE 13: Relationship between structure factor and friction radius. 


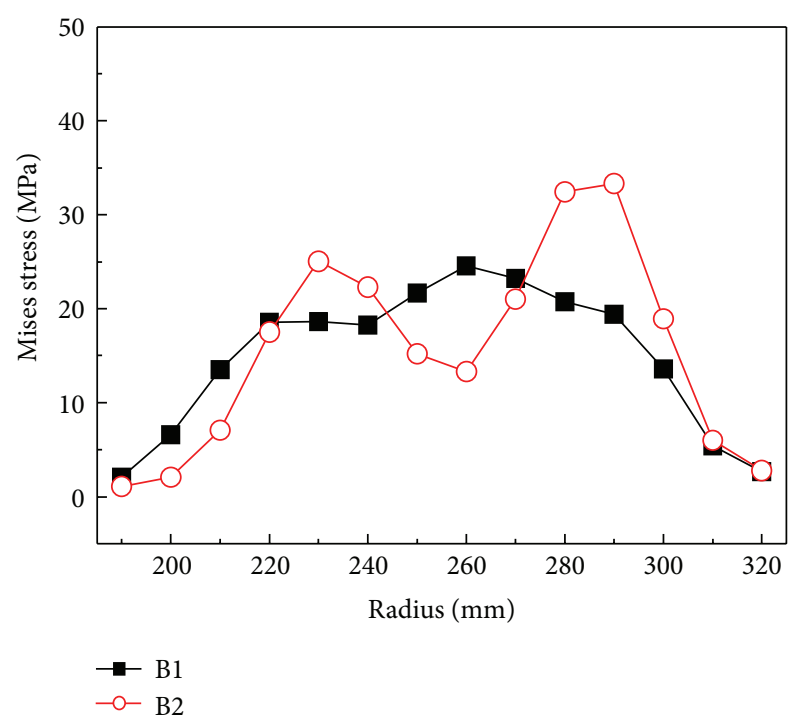

(a)

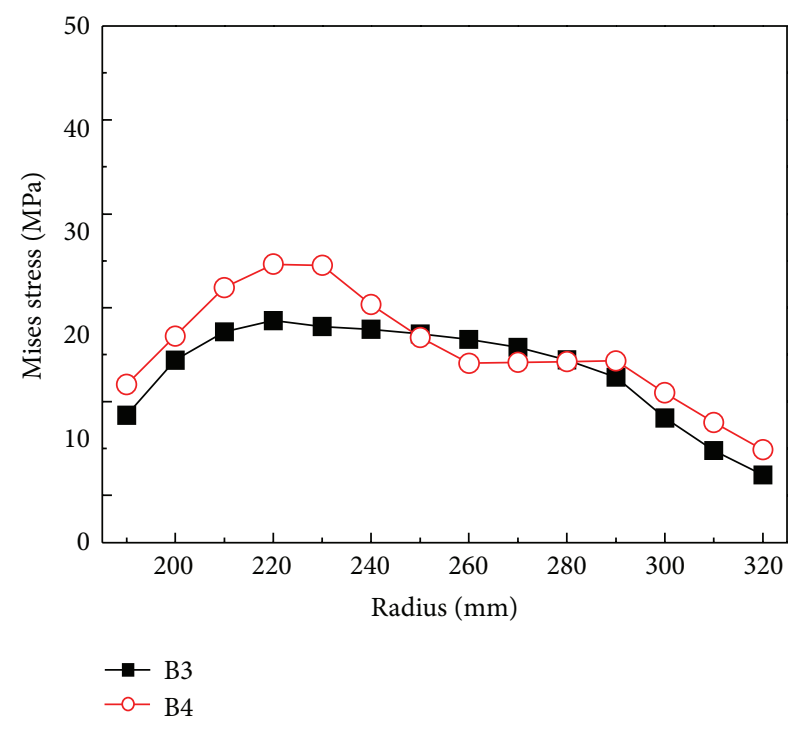

(b)

FIGURE 14: Relationship between thermal pressure and friction radius.

introduced. The radial structural factor reflects the distribution pattern of friction power on brake disc in radial direction; the circumferential structural factor reflects the distribution pattern of friction power in circumferential direction. The larger the radial structural factor and the smaller the circumferential structural factor the more uniform the temperature distribution on the brake disc surface and the lower the maximum temperature on the disc surface.

(iii) Utilizing MATLAB to program brake pad structure optimization. The brake pads formed by 5 round friction blocks and 7 round friction blocks are optimized by reducing the largest radial structural factor and increasing the circumferential structural factor. The maximum temperature and stress on brake disc of the optimized brake pad of 5 friction blocks are $4.9 \%$ and $10.7 \%$ lower, respectively, than those of the optimized brake pad of 7 friction blocks.

\section{Acknowledgment}

The work was supported by the Scientific Research Project of Liaoning Provincial Education Department (Project no. L2013187).

\section{References}

[1] F. E. Kennedy Jr., "Surface tanperatures in sliding systems-A finite element analysis," Journal of Lubrication Technology, vol. 103, no. 1, pp. 90-96, 1981.

[2] X. Tian and F. E. Kennedy Jr., "Contact surface temperature models for finite bodies in dry and boundary lubricated sliding," Journal of Tribology, vol. 115, no. 3, pp. 411-418, 1993.

[3] G. Chenghui, H. Jianmeng, and L. Xiezhao, "Heat dynamics study progress of disc brake friction wear," Chinese Journal of Construction Machinery, vol. 4, no. 1, pp. 83-88, 2006.
[4] P. Zagrodzki, K. B. Lam, E. Al Bahkali, and J. R. Barber, "Nonlinear transient behavior of a sliding system with frictionally excited thermoelastic instability," Journal of Tribology, vol. 123, no. 4, pp. 699-708, 2001.

[5] J.-S. Li, H.-T. Lin, and H.-P. Li, "Simulation analysis on the alloyforge steel brake disc temperature field for a high-speed train," Journal of the China Railway Society, vol. 28, no. 4, pp. 45-48, 2006.

[6] Q. Ding and J.-L. Xie, "Temperature field and stress field calculation of brake disc based on 3-dimension model," Journal of the China Railway Society, vol. 24, no. 6, pp. 34-38, 2002.

[7] J. Zheng, X. Guo, Z. Bao et al., "FEM analysis of the thermal stress in the brake disc for speed elevated passenger cars," Locomotive \& Rolling Stock Technology, vol. 3, pp. 4-6, 2002.

[8] Y. Ying and W. Gang, "3D transient temperature field and stress field simulation of vehicle brake disc," Mechanical Science and Technology, vol. 24, no. 10, pp. 1257-1260, 2005.

[9] C. H. Gao and X. Z. Lin, "Transient temperature field analysis of a brake in a non-axisymmetric three-dimensional model," Journal of Materials Processing Technology, vol. 129, no. 1-3, pp. 513-517, 2002.

[10] X. Lin and C. Gao, "Numerical simulation of non-axial symmetry temperature field of brake disc in emergency braking process," in A Collection of Papers of 7th China Tribology Congress, vol. 4, pp. 381-384, 2002.

[11] Z. Yang, J. Han, W. Li, Y. Chen, and J. Wang, "Thermomechanical coupling simulation of braking process of brake disc," Journal of Mechanical Engineering, vol. 46, no. 2, pp. 8892, 2010.

[12] S. Zhou, Y. Yang, and J. Xie, “Transient temperature and thermal stress distribution simulation analysis of high-speed train brake disc," Journal of Mechanical Engineering, vol. 47, no. 22, pp. 5560, 2011.

[13] J.-H. Luo et al., "The finite element thermo analysis of brake discs for trailers in multiple units," Rolling Stock, vol. 47, no. 4, pp. 22-24, 2009. 

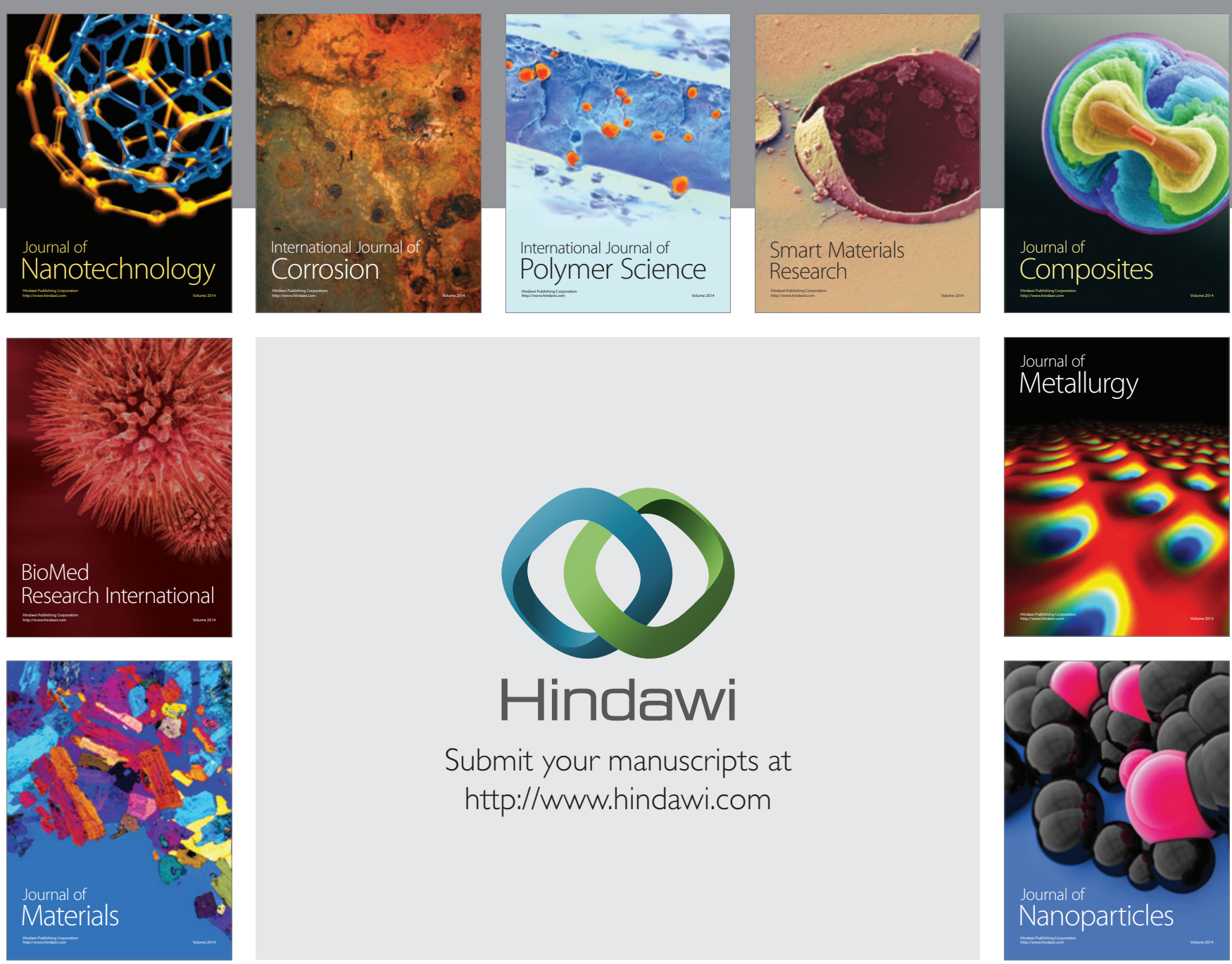

Submit your manuscripts at http://www.hindawi.com
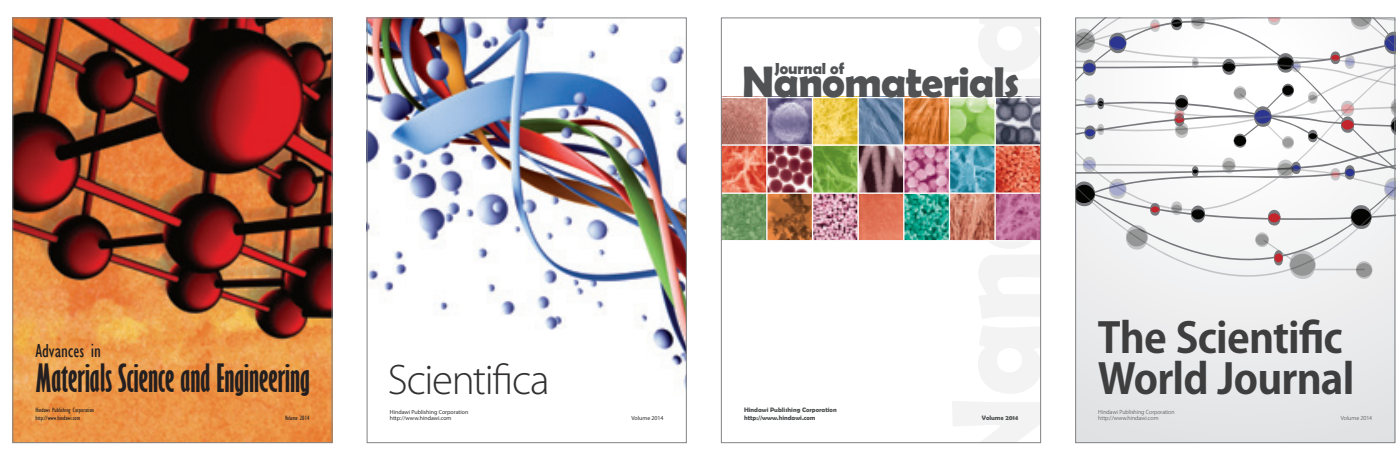

\section{The Scientific World Journal}
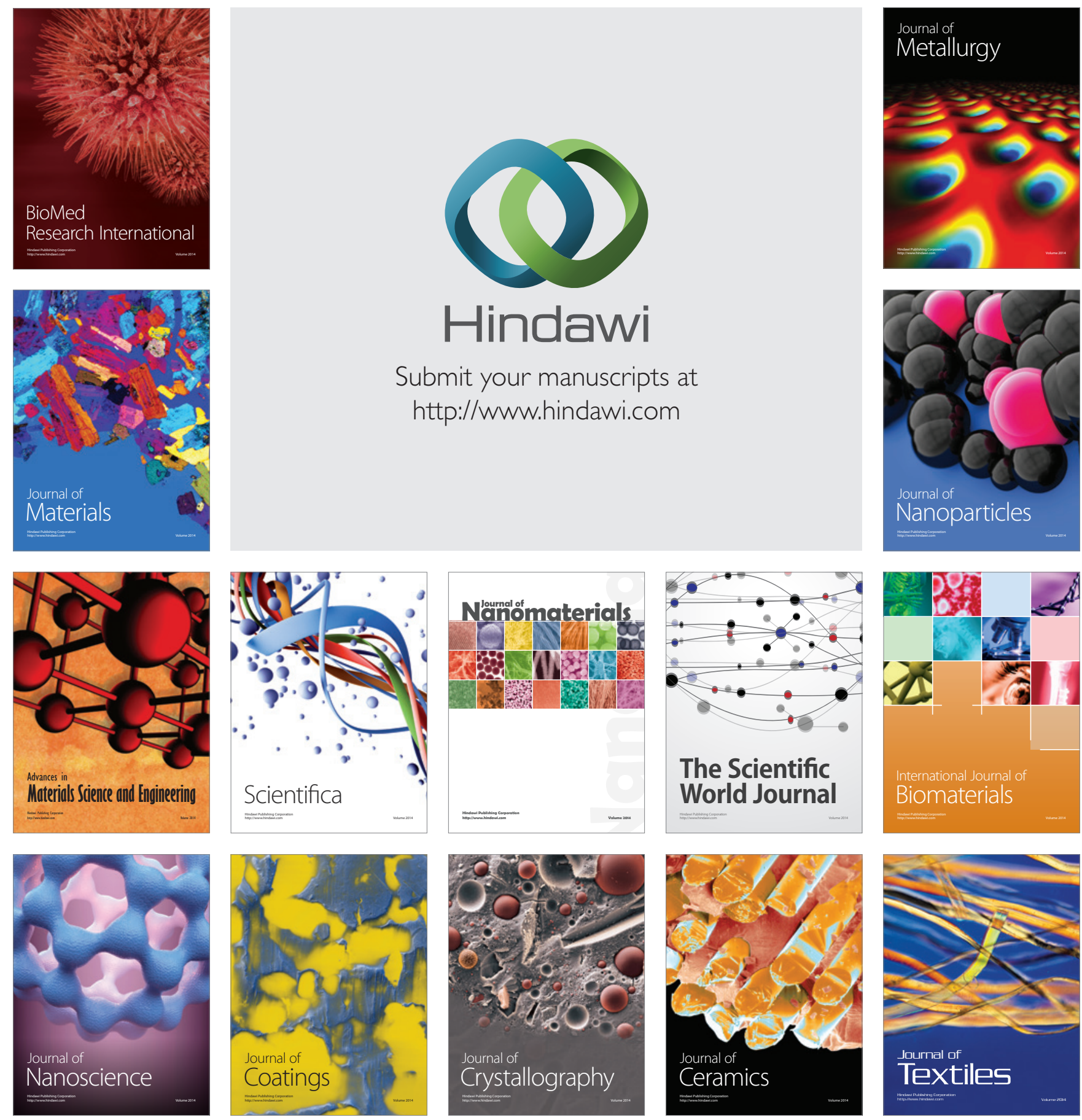